\title{
Evolución de las preferencias políticas y de políticas públicas entre el sector popular y el resto de la sociedad chilena entre 1990 y 2012*
}

\author{
Felipe Barrueto, ${ }^{* *}$ Patricio Navia ${ }^{* *}$
}

Perfiles Latinoamericanos | Ensayo
vol. 23 | núm. $46 \mid 2015$

pp. 61-89

\begin{abstract}
Resumen
La combinación de un rápido crecimiento económico con altos niveles de desigualdad, en el Chile posterior a 1990, permitió el desarrollo de una clase media emergente y la consolidación de diferencias entre los sectores altos y los nuevos sectores medios. El aquí llamado sector popular mejoró sus ingresos y sus expectativas, pero los sectores altos mejoraron aún más. ¿Qué efectos tuvo esto sobre las preferencias e inclinaciones políticas del sector popular y sobre sus prioridades de políticas públicas? ¿Qué tan diferente ha sido su evolución? Aunque al comenzar la nueva fase democrática los sectores medios y bajos prefirieron la Concertación, esa adhesión ha disminuido con el tiempo. Usando datos del Centro de Estudios Públicos, analizamos tanto la evolución del sector popular respecto del resto de la sociedad, como su propia evolución en las preferencias políticas y prioridades de políticas públicas.
\end{abstract}

\begin{abstract}
The combination of rapid economic development and high inequality in post-1990 Chile allowed for the development of an emerging middle class and the consolidation of differences between it and higher income groups. The popular sector improved its income and expectations, but the improvement in the high income group was more pronounced. What effects did this unequal improvement have on the electoral and public policy preferences and political inclinations of the popular sector? How different have the evolution been among the popular sector and the rest of the population? Though the low and middle class favored the center-left Concertación in the early phase of democracy, that support has decreased overtime. Using Centro de Estudios Públicos polling data, we analyze the evolution in political and public preferences of the popular sector with respect to the rest of the society.
\end{abstract}

Palabras claves: preferencias políticas, consolidación democrática, sector popular, encuestas, Chile. Keywords: political preferences, democratic consolidation, popular sector, public opinion polls, Chile.

* Este artículo fue parcialmente financiado por los proyectos Fondecyt Regular 1120638 y 1140072 . Y por el proyecto CONICYT/FONDAP/15130009. Agradecemos los comentarios de los revisores anónimos de la revista y comentarios de nuestros colegas del Observatorio Electoral de la UDP. Los errores u omisiones son de nuestra responsabilidad.

** Universidad Diego Portales.

*** Universidad Diego Portales / New York University. 
uando se produjo el retorno a la democracia en 1990, el 40\% de los chilenos vivía en condición de pobreza. Muchos otros cuyos ingresos los ponían por sobre el nivel de pobreza estaban también en posición de vulnerabilidad. Veinte años después, si bien solo un $15 \%$ de la población vive en pobreza, se puede hablar de sectores vulnerables que son claramente distinguibles de los grupos que tienen condiciones de vida estables. Precisamente porque ha disminuido la pobreza pero persisten altos niveles de desigualdad, hay buenas razones para evaluar las preferencias políticas y de políticas públicas del sector popular (pobres o personas apenas por sobre el nivel de pobreza) y compararlos con otros grupos de la sociedad.

Siguiendo una tradición de los estudios socioeconómicos, definimos a los grupos de menos ingresos como sector popular. Discutimos primero este concepto y la conveniencia de usarlo para diferenciarlo de los sectores estables y de mayor ingreso. Si bien la pobreza ha disminuido, los altos niveles de desigualdad que prevalecen en Chile justifican diferenciar entre grupos socioeconómicos que siempre han sido más acomodados y el sector popular. Luego explicamos la metodología que usamos para definir sector popular y analizamos resultados de encuestas usando esa categoría. Posteriormente, se examina su evolución en las preferencias políticas y de políticas públicas entre 1990 y 2012 y comparando con lo que ha ocurrido en otros grupos.

\section{El sector popular}

Tradicionalmente, los autores definen categorías sociales e identifican sus discursos para explicar e interpretar sus intenciones y preferencias. La concepción del sector popular depende estrictamente del criterio utilizado para definir la categoría; por ejemplo, puede ser definido por procesos culturales (Skeggs, 2004), discursos ideológicos (Salazar, 2011) o condiciones laborales (Crompton, 2010). Incluso hay teorías que sugieren su inexistencia $-\mathrm{y}$ la de otros grupos-, producto de la individualización del sujeto en el sistema económico neoliberal (Bauman, 2001). Las distintas concepciones sobre cómo se organizan los grupos sociales constituyen una situación de conflicto entre autores que buscan representar una misma realidad desde distintos prismas. A continuación describimos los fundamentos teóricos que establecen categorías sociales para definir la concepción de sector popular que aquí utilizamos.

La teoría de clase marxista hace un intento por definir categorías sociales. El modelo de Marx sostiene que las clases están determinadas por sus funciones en el modelo de producción. Existe una clase que domina el modelo 
(burguesía) y ejerce un poder sobre aquellos que solo pueden vender su mano de obra (el proletariado). A partir de este contexto se construye la conciencia de clases, produciendo una lucha irreconciliable entre opresores y oprimidos (Marx, 1997). Si bien la clase proletaria a menudo se asocia con el sector popular, la definición de Marx supone un conflicto entre clases. En tanto que, al hablar del sector popular, nosotros no suponemos necesariamente la existencia de dicho conflicto.

A diferencia de Marx, Weber crea otra distinción, basada en la capacidad de ingreso de los sujetos, sus intereses para poseer bienes y sus capacidades para posicionarse en el mercado (Weber, 1922). Según Weber, la posesión o carencia de un bien son fundamentales para definir las categorías y las características de una clase. El mercado y las capacidades del sujeto facilitan un estilo de vida según la demanda y oferta, clasificando a las personas en distintos estatus sociales. Así, desde Weber, el sector popular sería la parte más baja de una escala de estratificación basada en la situación económica y preferencias de los sujetos (Weber, 1922).

Desde el constructivismo, por su parte, Bourdieu presenta un análisis de las clases sociales, anunciando que "los agentes son clasificados y clasificadores" (Bourdieu, 2000: 102). Tanto las personas como los científicos sociales plantean parámetros y clasificaciones que se encuentran en constante conflicto o lucha simbólica (Bourdieu, 1987). Para Bourdieu, "las clases sociales son definidas y caracterizadas — en cierto modo — como conjuntos de agentes que por el hecho de ocupar posiciones parecidas en el espacio social (esto es, en la distribución de poderes) [se pueden agrupar] al desarrollar prácticas similares" (Bourdieu, 2000: 110). En consecuencia, la concepción de sector popular depende de las prácticas similares que provoca la posición del sujeto en la escala de poder. A partir de Bourdieu, entonces, la pertenencia al sector popular se debería ya sea a la clasificación objetiva y/o subjetiva que sobre ella realizan las personas y la que tiene la propia persona sobre sí misma.

En América Latina se han considerado los conceptos desarrollados por Weber y Bourdieu para definir el sector popular. En ellos, el trabajo está relacionado con diferentes premios, lo que da lugar a diferentes clases (Atkinson, 2010; Rojas, 2010). Por lo tanto, la situación de clase se asocia a la posición ocupada por los sujetos en el mercado, a partir de su condición laboral y de su capacidad de consumo. Siguiendo a Weber y a Bourdieu, definimos al sector popular desde una experiencia en común, delimitada por la posición de poco poder que tienen los sujetos pertenecientes a este grupo.

En estudios sobre el desarrollo político y económico chileno, el concepto de sector popular ha estado ampliamente presente, tanto antes de 1973 (De Vylder, 1976; Matterlat, Castillo, y Castillo, 1970; Debray, 1971; Petras, y 
Morley, 1975; Rojas, 1975; Garcés, 1976; Arriagada, 1974; Loveman, 1974; Kaufman, 1972) como durante el gobierno militar y en el periodo democrático actual (Oxhorn, 1991; Oxhorn, 1995; López, 2004; Larraín, 2001; Valdés, 1988; Posner, 2003, 2008). El concepto se define, aunque normalmente no de forma explícita, a partir de una pertenencia a los sectores en los eslabones más bajos de la escala social. El sector popular es aquel que está por debajo de la clase media. De hecho, tradicionalmente, la pertenencia al sector popular se asociaba con vivir en zonas humildes o con estar en situación de pobreza. Incluso algunos lo asociaban con una mayor predisposición a apoyar partidos políticos de izquierda o iniciativas de cambio social revolucionario (Garcés, 1976; Petras, y Zeitlin, 1967; Zeitlin, y Petras, 1970; Petras, 1972; Leiva, y Petras, 1986).

La identificación con el sector popular se basa en el sentido de inferioridad respecto de otros grupos, no necesariamente en una cuestión de clase social. Según Torres (2010), las personas que integran el sector popular reconocen como un "nosotros" a aquellos que se clasifican y son clasificados como parte del último escalón de la estratificación social. En tanto Sunkel (1987) y Mata (1991) muestran que el sector popular no solo representa ingresos en común, sino que los ciudadanos que lo integran tienen calles, periódicos, comunas, colegios, vacaciones e, incluso, objetivos de vida similares. Por ejemplo, en Chile podemos encontrar personas que tienen altos ingresos y se siguen identificando con el sector popular porque comparten códigos, consumo y espacios con personas que perciben el ingreso mínimo. Así, el sector popular supera los márgenes de la clase más baja de la estratificación de Weber. De hecho, a la posición de mercado se suman aquellos signos que reflejan el sentido de inferioridad del sector popular respecto de otros grupos. Siguiendo a Bourdieu, la condición de sector popular incluye también consideraciones que no están directamente asociadas al ingreso, sino que incorporan elementos subjetivos y objetivos que definen un grupo de la sociedad que si bien puede estar sobre la línea de pobreza, no se considera —o no es vista por otros- como parte de la clase media.

La identificación con el sector popular responde a categorías subjetivas que no siempre guardan relación directa con la pobreza. Se puede ser popular sin ser pobre. De ahí que usamos sector popular para referirnos a aquellas personas que pertenecen al grupo cuyos ingresos y cuya condición social no los hace partícipes de lo que comúnmente se denomina clase media, en tanto se mantienen en situación de vulnerabilidad o están apenas por sobre la línea de la pobreza. Por eso, deliberadamente, distinguimos entre pobreza y sector popular. La pobreza es una categoría que se define a partir de criterios técnicos. Aunque pueden ser también controversiales, las mediciones de pobreza aspiran 
a identificar criterios objetivos que permitan comparaciones entre casos y en el tiempo (Rojas, 2010; Millán, 2001; Vázquez, y Panadero, 2009; Castañeda, 1992; Contreras, 2003; Hojman, 1996).

El cuadro 1 muestra la disminución de la pobreza y de la indigencia a partir de datos oficiales de la Encuesta de Caracterización Socioeconómica Nacional (CASEN). Los chilenos en situación de pobreza disminuyeron de 38.6\% en 1990 a $14.4 \%$ en 2011. Aquellos en situación de extrema pobreza pasaron de un 13\% en 1990 a un $2.8 \%$ en 2012.

Cuadro 1. Evolución de la pobreza e indigencia en Chile, 1990-2012

\begin{tabular}{lcccccccccc}
\hline & 1990 & 1992 & 1994 & 1996 & 1998 & 2000 & 2003 & 2006 & 2009 & 2012 \\
\hline \% de pobres & 38.6 & 32.9 & 27.6 & 23.2 & 21.7 & 20.2 & 18.7 & 13.7 & 15.1 & 14.4 \\
$\begin{array}{l}\text { \% de personas en } \\
\text { extrema pobreza }\end{array}$ & 13.0 & 9.0 & 7.6 & 5.8 & 5.6 & 5.6 & 4.7 & 3.2 & 3.7 & 2.8 \\
\begin{tabular}{l} 
Coeficiente Gini \\
\hline
\end{tabular} & 0.57 & 0.58 & 0.58 & 0.57 & 0.58 & 0.57 & 0.55 & 0.54 & 0.55 & n.a. \\
\hline
\end{tabular}

Fuente: Elaboración propia con datos de la CASEN.

Si bien el indicador oficial de pobreza disminuyó drásticamente luego del retorno a la democracia y se comenzó a hablar de la consolidación de una clase media, la realidad de muchos se mantuvo definida por su condición de vulnerabilidad, que agrupa a aquellos cuyos ingresos los ponen apenas por sobre la línea de la pobreza o cuya precariedad de empleo los deja especialmente cerca de caer nuevamente en pobreza (PNUD, 2002; 1998). Así, aunque haya diferencias materiales y conceptuales entre pobreza y vulnerabilidad, amerita desarrollar un concepto que permita identificar a esa población que antes era clasificada como pobre y ahora es definida como vulnerable o de clase media emergente. Utilizamos el concepto de sector popular para definir a ese grupo de personas. Aunque su posición absoluta en la escala de ingresos y acceso a bienes haya mejorado, su posición relativa los asocia con los sectores de menos recursos.

\section{Sector popular y grupos socioeconómicos (GSE)}

Una forma de estudiar el sector popular y la evolución en sus preferencias es a través de encuestas de opinión pública. Para poder identificar al sector popular, debemos utilizar las herramientas disponibles en las propias encuestas. Si bien es un proxy limitado, asociamos el sector popular a una clasificación ampliamente usada en encuestas de opinión, el grupo socioeconómico (GSE). Esta categorización es compatible con el componente de mercado introducido 
por Weber, y perfeccionado por Bourdieu, que añade elementos subjetivos a la definición de clase. Precisamente porque la definición de GSE se construye a partir de una combinación de elementos objetivos y subjetivos, su utilización es apropiada para referirnos al sector popular.

El GSE no se construye preguntando directamente a los encuestados su identificación con una clase socioeconómica. Cuando el encuestador se presenta en un hogar, observa diferentes indicadores para asignar el GSE al que pertenece el encuestado. Entre estos indicadores destacan la comuna donde vive la persona, su barrio, sus pertenencias y la manera de expresar su opinión. Tomando en cuenta estas características objetivas y subjetivas (como el vestuario o la manera de expresarse, cuestiones que pudieran reflejar cosas más complejas que solo el ingreso), el encuestador clasifica a la persona en un GSE.

En Chile, normalmente, se utilizan cinco categorías de GSE. Ordenadas de la más alta a la más baja, $\mathrm{ABC} 1, \mathrm{C} 2, \mathrm{C} 3, \mathrm{D}$ y E. Mientras la primera se asocia con los grupos de más ingresos y mayores niveles de educación que residen en zonas con propiedades de más valor (la llamada clase alta), la segunda, el C2, se asocia con personas de ingresos medios. El C3, con personas de clase media a secas. El D es el principal indicador de clase media baja, mientras que en el E se agrupan las personas más humildes (lo que en años recientes se asociaría con vivir bajo el nivel de la pobreza). En general, en la construcción del GSE se utilizan la comuna de residencia, el nivel de educación, bienes y rango de ingreso (Adimark, s.f.). Nosotros utilizamos la clasificación en los grupos D y E como identificación de pertenencia al sector popular.

Ya que la asignación de GSE la realiza el encuestador, la clasificación pudiera ser controvertida. Por ejemplo, un comerciante de ingresos medios, pero bajos niveles de educación, residente en una comuna popular, pudiera ser clasificado como $\mathrm{C} 2$ o $\mathrm{C} 3$; mientras alguien que reside en una de altos ingresos, pero sin buena situación económica, pudiera ser clasificado como ABC1. Precisamente esos sesgos permiten asociar el GSE a la condición de sector popular. Una persona de larga residencia en una comuna pudiente, aunque tenga bajos ingresos temporales o permanentes, posiblemente tendrá menos identificación con el sector popular que un comerciante de buenos ingresos que reside en una de bajos ingresos. Ahora bien, debido a la forma en que se asigna, sería erróneo suponer una identificación o un sentido de pertenencia a una comunidad imaginaria en todas las personas clasificadas en el mismo GSE. El GSE no es identificación de clase (como sí lo pudiera ser una pregunta sobre identificación con la clase obrera), sino que clasifica respecto a un imaginario social presente en el propio encuestador.

La definición de cada GSE se construye a partir de diferencias observables. El encuestador observa límites que separan a los grupos. Por ejemplo, el gru- 
po $\mathrm{ABC} 1$ limita con algunas características del C2. Esta diferencia solo se presenta a nivel material. No supone una diferencia de visiones de mundo, ideología, o incluso discursiva, entre miembros de distintos grupos (Howarth, 2006). Esto es porque no hay evidencia de discurso común defendido por personas categorizadas en un mismo GSE. Por lo tanto, no se puede decir que las preferencias del grupo $\mathrm{ABC}$, por ejemplo, provengan de una noción hegemónica del grupo.

Además, como dice Larraín (2001), no es posible adjudicar características psicológicas a un grupo de personas a partir de una clasificación realizada por un encuestador. Si bien son evidentes las diferencias entre los distintos GSE, cada uno de estos no constituye una identidad distinta o comunidad imaginaria en particular (Anderson, 1993). Una residente de la comuna de clase media histórica de Núñoa y otra de la popular de Peñalolén pueden ser categorizadas como C2. Sin embargo, ambas mujeres no necesariamente son parte de un grupo, en tanto no se autodefinen como tal, ni reconocen la existencia de mismidad (Taylor, 1993; Tugendhat, 1996, Kymlicka, y Norman, 1997).

Encontrar diferencias entre las preferencias de distintos GSE no implica que estas den pie a movimientos sociales o iniciativas de cambio construidas a partir de identidades colectivas. En esencia, pertenecer al D no equivale a ser miembro de la clase obrera. Esas categorías anteriores suponían intereses de grupo que compartían el mismo discurso. Ser miembro de la clase obrera supone una pertenencia a una identidad colectiva, a una comunidad imaginaria. En cambio, ser clasificado como D refleja la percepción del encuestador sobre la situación socioeconómica del encuestado, esto es, sobre los bienes materiales y signos sociales que posee en el momento.

Así, los GSE devienen en categorías que describen un contexto social parecido en términos de mercado. Operacionalizar el sector popular en los GSE D y E nos permite estudiar sus preferencias políticas y de políticas públicas. La clasificación de GSE se aproxima, no refleja con exactitud la pertenencia al sector popular.

\section{Las preferencias de la gente}

¿Qué tan distinto es el sector popular del resto de la población? ¿Cómo han evolucionado sus preferencias y prioridades desde el retorno a la democracia en 1990 y hasta 2012?

Las escuelas de Columbia, Michigan y Rochester se centran en elementos de largo, mediano y corto plazo, respectivamente, para explicar preferencias electorales (Lau, y Redlawsk, 2006; Lewis-Beck, y Stegmaier 2007; Dalton, y Klingemann, 2007). Columbia sugiere que variables de largo plazo, como la 
religión, clase o etnia, son determinantes en las preferencias. Las personas definen su ideología a partir de clivajes sociales que marcan la formación y alineamiento de los partidos políticos y de las preferencias de los ciudadanos (Lau, y Redlawsk, 2006; Dalton, y Klingemann, 2007). Michigan enfatiza la socialización política de mediano plazo (Lau, y Redlawsk, 2006; Dalton, y Klingemann, 2007; Jennings, 2007; Campbell et al., 1960). En cambio, Rochester destaca variables de corto plazo. Variables económicas, como empleo, inflación, crecimiento, la percepción sobre la delincuencia, o valores morales, cargan la balanza en la apreciación sobre el desempeño del gobierno saliente y sobre su decisión de voto.

$\mathrm{Al}$ agrupar a la gente en tanto su pertenencia al sector popular inevitablemente suponemos que las variables de mediano y largo plazo influyen en su intención de voto. Por cierto, la complejidad de variables que inciden en la decisión del voto - y el peso específico de cada variable - dificultan la elaboración de modelos predictivos. La incertidumbre sobre variables de corto plazo, como el desempeño de la economía, dificulta nuestra capacidad predictiva.

Al estudiar al sector popular, y la evolución de sus preferencias y prioridades, podemos evaluar la correspondencia con modelos que enfatizan cuestiones de mediano y largo plazo, por ejemplo, si el sector popular ha mostrado estabilidad en sus preferencias electorales y de políticas públicas. Además, podemos comparar la evolución en sus preferencias con la evolución observada en los demás grupos de la sociedad. Por último, podemos medir las diferencias iníciales en preferencias políticas y de políticas públicas entre el sector popular y otros grupos para ver cómo evolucionaron durante el periodo. Estas dos tesis son los ejes centrales de la comparación que realizamos. Formalmente, presentamos dos hipótesis:

- H1: Las preferencias electorales y de políticas públicas del sector popular se mantuvieron estables en el periodo.

- H2: Las diferencias en preferencias políticas y de políticas públicas entre el sector popular y otros grupos de la sociedad se mantuvieron durante el periodo.

\section{Contexto político chileno, 1990-2012}

Entre 1990 y 2012, la política chilena ha permanecido influida por los sucesos que determinaron el golpe militar de 1973, la dictadura (1973-1990) y la forma en que se produjo la transición a la democracia. El plebiscito de 1988 y las elecciones de 1989 - que dieron la victoria a la centroizquierdista Concertación-facilitaron la transición hacia la democracia vía transacción (Cañas, 
1997) o transición pactada (Godoy, 1999). Durante la década de 1990, la Concertación tuvo supremacía electoral, dejando en minoría al bloque de derecha, la Alianza. Los partidos de derecha fueron estigmatizados por haber sido parte del complejo legado del régimen autoritario. Como muestra el cuadro 2, la derecha tuvo poco apoyo electoral después del retorno a la democracia. No obstante, con el paso de los gobiernos centroizquierdistas, las diferencias ideológicas entre la Concertación y la Alianza disminuyeron (Moulián, 1997; Portales, 2000). La normalización democrática ayudó al fortalecimiento electoral de la Alianza y debilitó el apoyo inicial a la Concertación.

\section{Cuadro 2. Resultados electorales en Chile por coalición, 1989-2012}

\begin{tabular}{|c|c|c|c|c|}
\hline \multirow{2}{*}{ Tipo de elección } & \multicolumn{3}{|c|}{$\%$ de votos } & \multirow{2}{*}{$\begin{array}{c}\begin{array}{c}\text { Número de votos } \\
\text { válidamente emitidos }\end{array} \\
\text { Total }\end{array}$} \\
\hline & Alianza & Concertación & Otros & \\
\hline 1989 Presidencial & 29.4 & 55.2 & 15.4 & 6979859 \\
\hline 1989 Diputados & 34.2 & 51.5 & 14.3 & 6797122 \\
\hline 1989 Senadores & 34.9 & 54.6 & 10.5 & 6800410 \\
\hline 1992 Municipal & 29.7 & 53.3 & 17.0 & 6410906 \\
\hline 1993 Presidencial & 24.4 & 58.0 & 17.6 & 6968950 \\
\hline 1993 Diputados & 36.7 & 55.4 & 7.9 & 6738859 \\
\hline 1993 Senadores & 37.3 & 55.4 & 7.2 & 1874127 \\
\hline 1996 Municipal & 32.5 & 56.1 & 11.4 & 6301298 \\
\hline 1997 Diputados & 36.3 & 50.5 & 13.2 & 5795773 \\
\hline 1997 Senadores & 36.6 & 49.9 & 13.5 & 4239366 \\
\hline 1999 Presidencial & 47.5 & 48.0 & 4.5 & 7055128 \\
\hline 1999 Presidencial (2v) & 48.7 & 51.3 & - & 7178727 \\
\hline 2000 Municipal & 40.1 & 52.1 & 7.8 & 6515574 \\
\hline 2001 Diputados & 44.3 & 47.9 & 7.8 & 6144003 \\
\hline 2001 Senadores & 44.0 & 51.3 & 4.7 & 1732415 \\
\hline 2004 Alcaldes & 38.7 & 44.8 & 16.5 & 6310206 \\
\hline 2004 Concejales & 37.7 & 47.9 & 14.4 & 6123375 \\
\hline 2005 Presidencial & $25.4 / 23.2$ & 48.6 & 5.4 & 6942041 \\
\hline 2005 Presidencial (2v) & 46.5 & 53.5 & - & 6959413 \\
\hline 2005 Diputados & 38.7 & 51.8 & 9.5 & 6601811 \\
\hline 2005 Senadores & 37.3 & 55.7 & 7.0 & 2574833 \\
\hline 2008 Alcaldes & 40.7 & 38.4 & 20.9 & 6362130 \\
\hline 2008 Concejales & 36.1 & 45.1 & 36.1 & 6086895 \\
\hline 2009 Presidencial & 44.1 & 29.6 & 26.4 & 6977544 \\
\hline 2009 Presidencial (2v) & 51.6 & 48.4 & - & 6958972 \\
\hline 2009 Diputados & 43.4 & 44.4 & 12.3 & 6615856 \\
\hline 2009 Senadores & 45.2 & 43.7 & 11.5 & 1895482 \\
\hline 2012 Alcaldes & 37.5 & 41.7 & 20.8 & 5542029 \\
\hline 2012 Concejales & 32.9 & 49.4 & 17.7 & 5331582 \\
\hline
\end{tabular}

Fuente: Elaborada por los autores con datos de Servicio Electoral, disponibles en <http://www.elecciones.gov.cl>. 
En las primeras elecciones presidenciales realizadas después de 1990, la Concertación recibió mayoría absoluta. En 1989, Patricio Aylwin obtuvo un $55.2 \%$, superando el $29.4 \%$ obtenido por el candidato de la Alianza. En 1993, el candidato presidencial de la Concertación, Eduardo Frei, obtuvo el 58\% de los sufragios. En cambio, en la presidencial de 1999, la Concertación no alcanzó la mayoría absoluta. Ricardo Lagos se impuso en segunda vuelta con un $51.3 \%$, la votación más baja recibida por la Concertación hasta entonces.

A partir del buen desempeño de la Alianza en 1999, todas las subsecuentes elecciones presidenciales se decidieron en segunda vuelta. La alta competitividad de 1999 se repitió en 2005, cuando la suma de los dos candidatos de la Alianza superó en votos a la candidata de la Concertación, Michelle Bachelet. Por primera vez, la Concertación fue superada en una elección presidencial. Sin embargo, las mujeres — que habían tenido más simpatía con el bloque conservador - apoyaron con más fuerza a Bachelet, lo que le permitió aumentar su votación en segunda vuelta y ganar esas elecciones (Morales, 2008).

En la presidencial de 2009, como muestra el cuadro 2, la selección del candidato y los conflictos internos de la Concertación llevaron a un quiebre que gatilló la renuncia al Partido Socialista del diputado Marco Enríquez-Ominami (ME-O), quien se presentó como candidato independiente en primera vuelta. Mientras Eduardo Frei, el candidato de la Concertación, recibió un 29\%, ME-O alcanzó un 20\%. Posteriormente, Sebastián Piñera —el candidato único de la Alianza - ganó la elección presidencial al captar parte de la votación de ME-O en segunda vuelta.

La mayor competitividad de la Alianza se evidenció también en elecciones legislativas. Si en 1997 la Concertación obtuvo 14.3\% más de votos que la Alianza, la distancia se redujo a un $3.6 \%$ en 2001. En 2005, la Alianza obtuvo 54 escaños, con un $37.3 \%$ de la votación, mientras la Concertación logró 65 escaños con el $55.7 \%$. En la contienda senatorial del mismo año, la Concertación obtuvo 11 escaños, la Alianza 8, y solo un independiente llegó al Senado. Si bien la Concertación volvió a ganar, las diferencias se estrecharon en 2009. La Concertación ganó en votos para diputados, pero fue superada en senadores. Ese año, la Concertación se unió al Partido Comunista en un pacto contra la exclusión, que obtuvo 9 de 18 senadores, igualando a la Alianza. En diputados, la Concertación apenas superó a la Alianza. Sin embargo, esta última obtuvo más escaños en la Cámara, tras obtener 58 de los 120 escaños. La Concertación y el PC sumaron 57 . El resto de los escaños fueron captados por dos independientes y tres descolgados de la Concertación.

El apoyo a la Concertación en elecciones municipales también comenzó a descender a partir de 2000. En 2004, ganó en alcaldes y concejales, pero sin mayoría absoluta. La Concertación obtuvo la victoria en 203 alcaldías, mientras que la 
Alianza se quedó con 104 de las 345 comunas del país. En 2008, la Concertación se presentó en dos listas. La división y las renuncias de militantes que se presentaron como independientes le costaron alcaldes y concejales a la Concertación, que obtuvo solo seis alcaldías más que la Alianza. En número de votos, la Alianza superó por primera vez a la Concertación ( $40.7 \%$ versus $38.4 \%)$. En cambio, en concejales, la Concertación obtuvo 1070 escaños, con el 45.1\% de votos; y la Alianza alcanzó 861 concejales, con el 36.1\%. En 2012, el desempeńo de la Concertación superó en todos los frentes a la Alianza. El nuevo sistema de inscripción automática y voto voluntario - que produjo una caída en la participación electoral- permitió que la Concertación obtuviera 167 alcaldías con el 41.7\% de los votos y 1168 concejales con el 49.4\%. En tanto la Alianza solo obtuvo 121 alcaldes y 832 concejales con el $37.5 \%$ y $32.9 \%$ de los sufragios, respectivamente.

\section{La evolución en las preferencias del sector popular}

Para evaluar las preferencias electorales y de políticas públicas del sector popular, usamos datos de la serie de encuestas del Centro de Estudios Públicos (CEP), realizadas periódicamente con muestras representativas del país. Los datos de las encuestas del CEP están públicamente disponibles y han sido ampliamente utilizados en estudios sobre preferencias de los chilenos (Morales, 2012, 2008; Segovia et al., 2008; Navia, 2010).

Entre 1990 y 2012 varió el peso relativo de cada GSE en las encuestas del $\mathrm{CEP}$, como lo muestra la gráfica 1 . Aunque la situación económica ha mejorado, las encuestadoras continúan asignando a la mayoría de las personas a los grupos socioeconómicos (GSE) C3 y al sector popular (los grupos D y E), mientras que los grupos $\mathrm{ABC} 1$ y $\mathrm{C} 2$ siguen siendo minoritarios para las empresas de medición. Esto puede ser interpretado como que los clasificados C3 en 2012 están en mejores condiciones que aquellos considerados C 3 en 1990. Pero, en términos relativos al resto de la sociedad, suponemos que las encuestas reflejan diferencias similares entre una persona considerada $\mathrm{ABC} 1$ y otra catalogada como $\mathrm{C} 3$ en 1990 que en 2012.

El peso relativo del $\mathrm{ABC} 1$ disminuyó, lo que presumiblemente refleja cambios en los criterios de clasificación. Después de experimentar un alza hasta 1994, el ABC1 ha venido a la baja. En 2012, el porcentaje de ABC1 es notoriamente inferior al $12.3 \%$ de 1990 . Lo mismo ha ocurrido con el C2. Por otra parte, el C3 muestra un comportamiento de $\mathrm{U}$, con porcentajes más altos a comienzos de los noventa y en años recientes. En cambio, el sector popular presenta una expansión hasta fines de los noventa y luego una disminución sostenida. No obstante, la mayor cantidad de personas — más del 80\%— está en C3 y en el sector 
popular. A comienzos de los noventa, un $50 \%$ de las personas eran clasificadas como C3. Hacia fines del cuatrienio de Aylwin, aparentemente por una modificación en el criterio de clasificación, eran 39.9\%. En paralelo a la caída del C3, se observa un aumento sostenido del sector popular, que supera el $60 \%$ a fines de los noventa. A partir de entonces, el sector popular baja en forma sostenida y el C3 aumenta con cierta inestabilidad. Finalmente, en 2012, ambos grupos son de tamaño similar (en torno al 40\%).

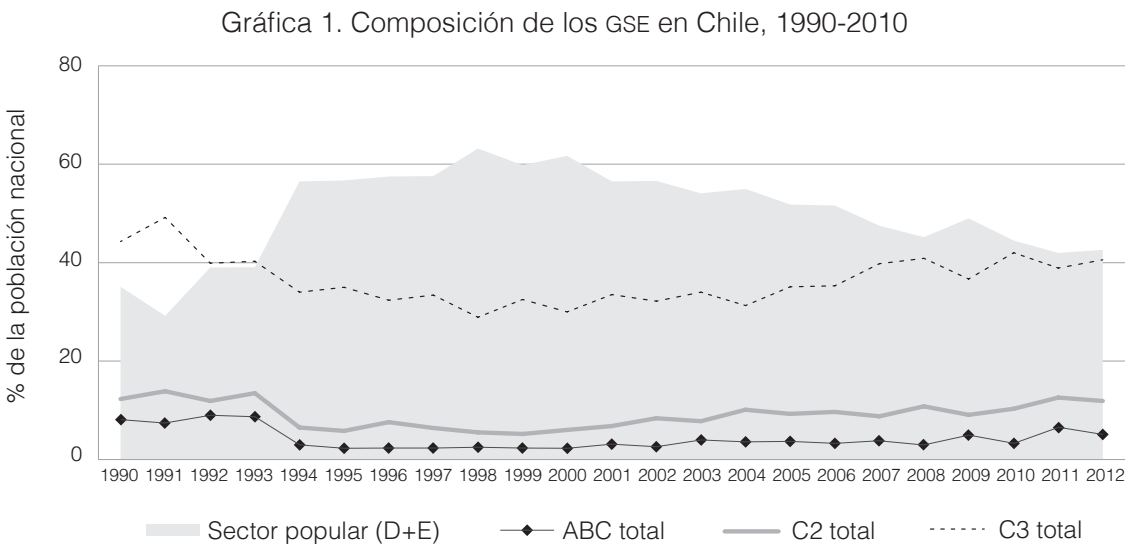

Fuente: Elaboración propia con datos de las encuestas del CEP, 1990-2012, disponible en <www.cepchile.cl>

\section{Las preferencias electorales del sector popular}

Las elecciones se han hecho más competitivas desde 1990. A partir de las últimas encuestas realizadas por el CEP antes de las elecciones presidenciales de 1993, 1999, 2005 y 2009, recopilamos la intención de voto en cada GSE. El cuadro 3 muestra diferencias en preferencias electorales entre el sector popular y los otros grupos. Mientras el ABC1 siempre apoyó con fuerza a la Alianza, el C2 y C3 abandonó a la Concertación a partir de 1999. En cambio, el sector popular ha sido más renuente a apoyar a los candidatos presidenciales de la coalición de derecha. De hecho, aunque el apoyo a la Concertación cayó en todos los grupos, esto sucedió con menos fuerza en el sector popular. La razón de votación por la Concertación en 1993 respecto a 2009 es inferior en el sector popular que en los otros grupos, como lo muestra el cuadro 3. Pero en la votación por los candidatos presidenciales de la Alianza, la razón 1993/2009 es similar en todos los grupos, incluso en el sector popular. Aunque la Alianza mejoró su votación en el sector popular, la Concertación perdió menos votación en ese sector que en los otros grupos. 


\begin{tabular}{|c|c|c|c|c|c|}
\hline Candidatos & $A B C 1$ & $C 2$ & C3 & Sector popular & Total \\
\hline \multicolumn{6}{|c|}{ Concertación } \\
\hline Frei 1993 & 27.5 & 56.2 & 58.6 & 66.8 & 58.7 \\
\hline Lagos 1999 & 18.2 & 35.2 & 35.3 & 43.1 & 39.9 \\
\hline Bachelet 2005 & 27.1 & 37.6 & 44.6 & 47.2 & 44.5 \\
\hline Frei 2009 & 9.6 & 13.8 & 20.9 & 36.3 & 26.7 \\
\hline Razón 1993/2009 & 2.9 & 4.1 & 2.9 & 1.8 & 2.1 \\
\hline \multicolumn{6}{|c|}{ Alianza } \\
\hline Alessandri 1993 & 45.0 & 19.2 & 17.8 & 12.1 & 18.2 \\
\hline Lavín 1999 & 68.2 & 46.3 & 41.1 & 35.4 & 38.2 \\
\hline Lavín + Piñera 2005 & 62.7 & 51.8 & 45.8 & 44.8 & 46.7 \\
\hline Piñera 2009 & 63.0 & 43.1 & 40.0 & 34.5 & 39.0 \\
\hline Razón 1993/2009 & 0.7 & 0.4 & 0.4 & 0.4 & 0.5 \\
\hline
\end{tabular}

Fuente: Elaboración propia con datos de las encuestas CEP, disponible en <http://www.cepchile.cl>.

Como también muestra la gráfica 2, la intención de voto del sector popular ha variado en el tiempo. Desde la elección de 1993 hasta la de 2005, hay un aumento en la intención de voto por la Alianza en todos los GSE. Pero en 2009, la intención de voto por la Alianza disminuyó en el sector popular respecto a 2005. Por otra parte, hay una baja sostenida en la intención de voto por la Concertación en dicho sector, salvo en 2005, cuando se revirtió la baja y Bachelet alcanzó $47.2 \%$ de esa intención de voto. Bachelet recibió más apoyo en 2005 que Lagos en 1999 en todos los GSE. De hecho, en ABC1, Bachelet tuvo una intención de voto sustancialmente mayor que Lagos. Así, aunque Bachelet revirtió la tendencia a la baja en el apoyo del sector popular a la Concertación, eso mismo aconteció en otros GSE. En 2009, el sector popular también apoyó al candidato de la Concertación más que los otros GSE; y aunque apoyó con menos fuerza a Frei en 2009 que a Bachelet en 2005, la caída en el apoyo a la Concertación entre 2005 y 2009 fue menos pronunciada en este sector que en los demás grupos.

La evolución de la intención de voto del sector popular en elecciones presidenciales es similar a la observada en otros grupos. Como muestra la gráfica 2 , ese grupo y el $\mathrm{ABC} 1$ presentan una disminución en la intención de voto por la Concertación desde 1993, con la excepción de 2005. En el caso de la Alianza, hay una tendencia similar al alza en la intención de voto del sector popular y el ABC1, solo que el mejor ańo para la Alianza en ABC1 fue 1999, mientras que en el sector popular fue en 2005. En 2009, la intención de voto por la Alianza en $\mathrm{ABC} 1$ se mantuvo respecto a 2005, pero en el sector popular disminuyó.

No hay evidencia para sustentar la hipótesis 1 . El sector popular no ha mostrado estabilidad en sus preferencias electorales en el periodo. En cambio, la 
evidencia para la hipótesis 2 es mixta. Las preferencias del sector popular por candidatos presidenciales de la Alianza convergen con las del C2 y C3 en elecciones recientes. Aunque el apoyo del sector popular a candidatos presidenciales de la Alianza ha aumentado, sigue siendo sustancialmente inferior al apoyo que esos candidatos suscitan en el $\mathrm{ABC} 1$. A su vez, aunque el apoyo del sector popular a la Concertación ha caído, todavía es superior que en otros GSE. Pese a ser menos votada en el sector popular hoy que hace veinte ańos, la Concertación sigue teniendo su mayor apoyo en ese grupo. De hecho, en 2009, cuando perdió por primera vez una elección presidencial, la Concertación superó a la Alianza en intención de voto en el sector popular. Por lo tanto, la hipótesis 2 se rechaza para la Alianza y se confirma para la Concertación.

Gráfica 2. Intención de voto en el sector popular y ABC1, 1993-2009

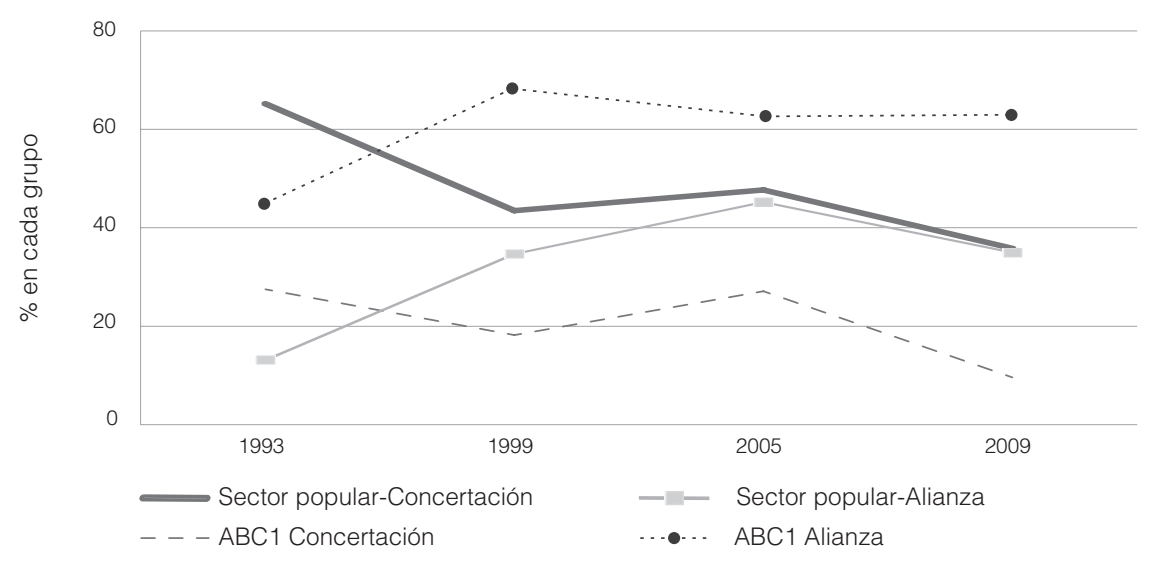

Fuente: Elaboración propia con datos de las encuestas CEP, disponible en <http://www.cepchile.cl>.

\section{Aprobación presidencial}

Los presidentes del periodo han sido Patricio Aylwin (1990-1994), Eduardo Frei (1994-2000), Ricardo Lagos (2000-2006), Michelle Bachelet (20062010) y Sebastián Piñera (2010-2014). Los cuatro primeros pertenecían a la Concertación y solo el más reciente pertenece a la Alianza.

La gráfica 3 muestra que Aylwin experimentó una caída similar en su aprobación en todos los GSE. La evaluación de su gestión en el sector popular cayó con más fuerza que en los otros GSE, pasando de un $62.8 \%$ al comienzo de su mandato a un 55.6\% en 1993. Si el primer gobierno de la Concertación expe- 
rimentó una luna de miel prolongada, esta duró menos con el sector popular que con los otros GSE.

La administración Frei se inició con una aprobación mayor en el sector popular que en los otros GSE. Pero también experimentó una tendencia a la baja en su aprobación en todos los GSE. Su caída fue todavía superior a la de Aylwin en el sector popular, llegando a un $40.2 \%$ de aprobación al final del periodo. La crisis asiática, y sus efectos negativos sobre el empleo, pudieran ser causa de la caída en la aprobación a Frei en todos los GSE. Pero la caída en la aprobación a Frei fue más pronunciada en el sector popular que en los otros GSE.

A diferencia de sus predecesores, Lagos fue el primer presidente en ver su aprobación final superar a su aprobación inicial en todos los GSE, aunque su gestión tuvo menos apoyo en el sector popular que en otros grupos. Lagos inició su periodo con un $50 \%$ de apoyo en el sector popular. Al término de su mandato, tenía $58.2 \%$. En la primera parte de su mandato, no hubo diferencias entre el sector popular y los otros GSE. Sin embargo, en la segunda mitad de su gestión, la aprobación a Lagos aumentó con mayor fuerza en los otros GSE que en el sector popular. Como bien señaló entonces un connotado líder del sector bancario, los empresarios aman a Lagos.

La presidenta Bachelet experimentó una rápida caída en su aprobación. Pero en la segunda mitad de su mandato, cuando se implementó la agenda de protección social, mejoró su aprobación en todos los sectores, especialmente en el sector popular. Su aprobación también subió en los otros GSE, lo que la llevó a tener la más alta aprobación presidencial desde 1990. Sin embargo, esta sostenida alza no fue uniforme en todos los GSE. A diferencia de Lagos, cuya aprobación fue superior en los GSE más altos, Bachelet obtuvo una mayor aprobación en el sector popular (Morales, y Saldaña, 2009).

El presidente Piñera muestra un patrón de aprobación distinto al de la presidenta Bachelet. Su aprobación es marcadamente superior en los GSE más altos. A su vez, Piñera logra menos apoyo en el sector popular. El contraste de las diferencias en aprobación presidencial entre el sector popular y los otros grupos es mayor precisamente cuando comparamos los gobiernos de Bachelet y Piñera. Mientras Bachelet era más valorada en el sector popular, Piñera alcanza sus niveles más bajos de aprobación en ese grupo.

Entonces, la evidente varianza en la aprobación presidencial del sector popular cuestiona nuestra primera hipótesis. Es más, resulta claro que la aprobación presidencial en el sector popular varió y de forma muy distinta que en otros GSE, especialmente durante los gobiernos de Bachelet y Piñera. Si bien al comienzo del periodo había pocas diferencias entre el sector popular y los otros GSE en aprobación presidencial, desde el gobierno de Lagos se evidencia una divergencia en la aprobación presidencial entre el sector popular y los otros grupos. En 
consecuencia, se cuestiona la segunda hipótesis. En los últimos periodos presidenciales se profundizan las diferencias entre el sector popular y los demás GSE.

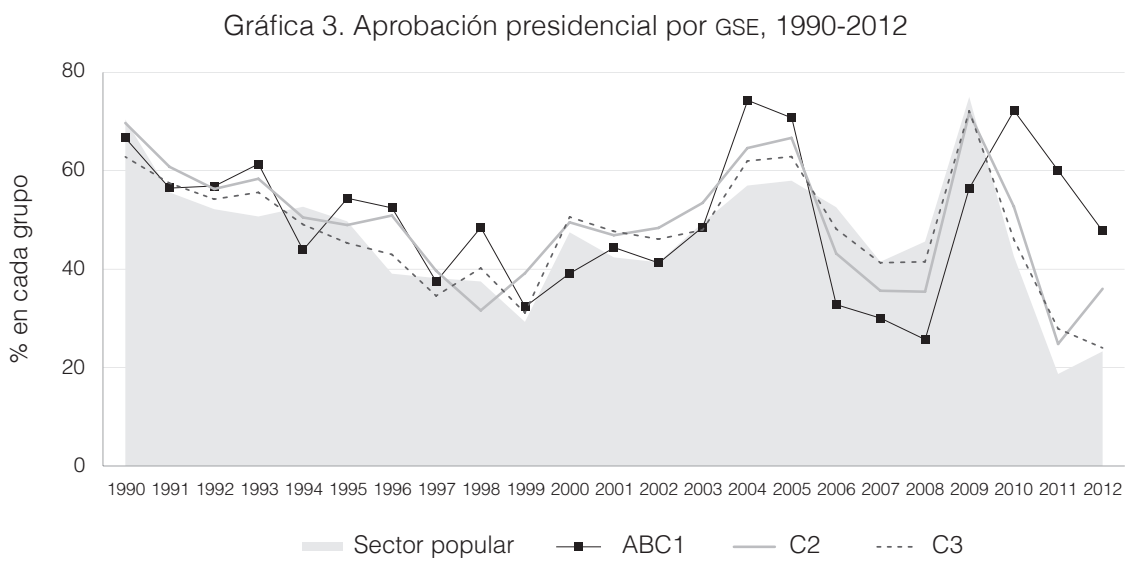

Fuente: Elaboración propia con datos de las encuestas del CEP 1990-2012, disponible en <www.cepchile.cl>.

\section{Identificación por coalición}

La identificación por coalición ha variado desde 1990 en el sector popular y en los otros GSE. De acuerdo a la gráfica 4 , en años recientes no existe una diferencia significativa en la identificación con la Concertación entre el sector popular y los otros grupos. Aunque a comienzos de la década de 1990, la Concertación recibía más apoyo en ese grupo que en los demás. Con el paso de los años, la identificación con la Concertación cayó en todos los grupos, pero más en el sector popular, lo que facilitó la convergencia con los otros grupos. Rechazamos así nuestra primera y segunda hipótesis.

En la Alianza, las diferencias en la identificación por GSE son mucho más pronunciadas, como lo presenta la gráfica 5 . Sistemáticamente, la Alianza tiene mucho menos apoyo en el sector popular que en los otros GSE. La Alianza ha mejorado su aprobación en los GSE más altos, pero su apoyo en el sector popular ha crecido a un ritmo tenue e inestable. Por lo tanto, no hay evidencia de que el sector popular haya convergido con los demás GSE en su nivel de apoyo a la Alianza (hipótesis 2).

Aunque el apoyo a la Concertación en el sector popular bajó - lo que cuestiona nuestra primera hipótesis sobre la estabilidad de sus preferencias-, el apoyo que dio a la Alianza se mantuvo relativamente estable — y no aumentó como en los otros grupos-, confirmando así lo planteado en nuestra primera hipótesis. 


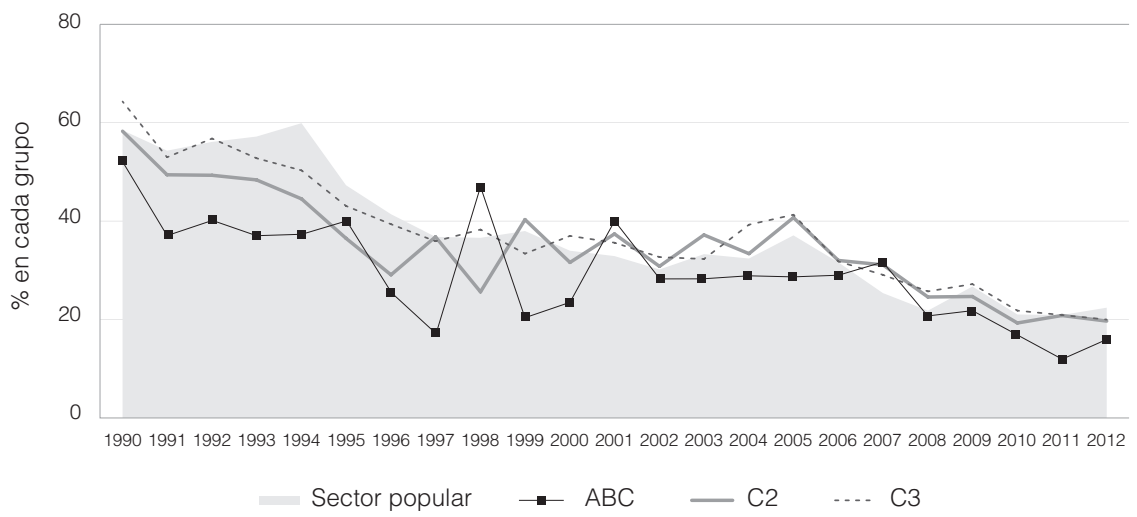

Gráfica 5. Identificación con la Alianza por GSE, 1990-2012

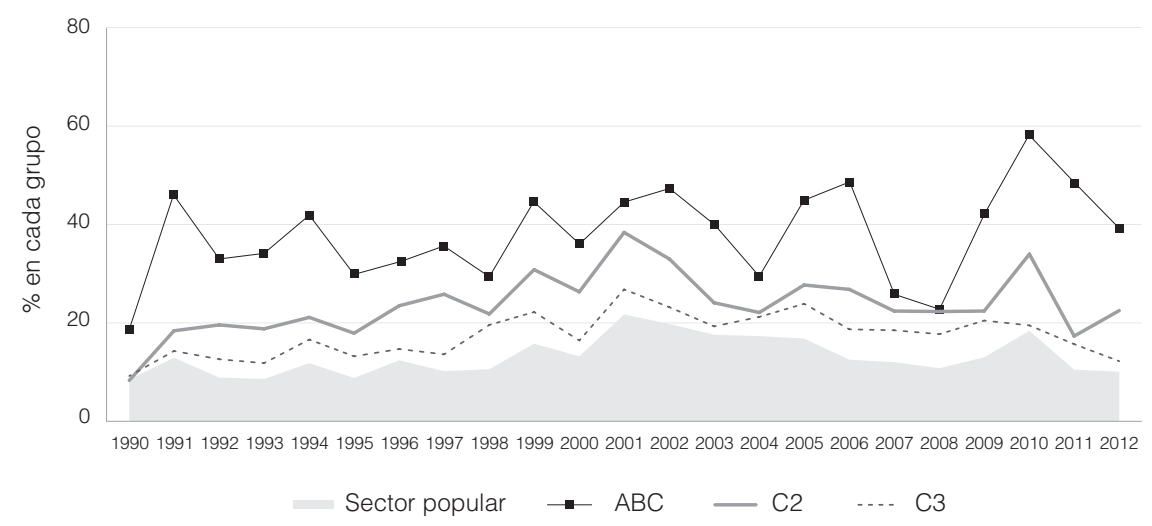

Fuente: Elaboración propia con datos de las encuestas CEP, 1990-2012, disponible en <www.cepchile.cl>.

\section{Prioridades de política pública por GSE}

En las encuestas del CEP, se han identificado históricamente campos de acción de las políticas públicas. Si bien son categorías determinadas por una pauta de la propia encuesta, podemos encontrar diferentes necesidades y preferencias entre los GSE. La encuesta del CEP interroga sobre los tres problemas a los que el gobierno debería dedicar más tiempo. Las alternativas varían un poco a través de los ańos, pero destacan la delincuencia, empleo, educación, sueldo y salud, que sistemáticamente aparecen como prioridades. Cuando la encuesta muestra un bajo interés por alguna de estas alternativas, no deberíamos concluir que 
un GSE no esté preocupado por esa prioridad, sino que hay otras que ese mismo GSE considera más apremiantes para la acción del gobierno.

La delincuencia es la alternativa más mencionada como prioridad a la que debe abocarse el gobierno. La gráfica 6 evidencia que, desde comienzos del periodo, la delincuencia ha sido un problema relevante. Aunque cayó a mediados de los noventa, la preocupación por la delincuencia ha vuelto a crecer en todos los GSE en años recientes. Si bien evoluciona en el tiempo en forma de U, la preocupación sobre ese rubro sigue siendo menor hoy que cuando recién se recuperó la democracia (salvo en el grupo $\mathrm{ABC} 1$, el de más ingresos).

La preocupación por la delincuencia en el sector popular ha sido inestable en el periodo, variando entre 35 y $60 \%$. Sin embargo, se ha movido a la par que en los demás GSE y generalmente se ha mantenido más baja. Esto cuestiona nuestra primera hipótesis, pues la tendencia de ese sector para este rubro es inestable. A mediados de los noventa, la preocupación por la delincuencia cayó con más fuerza entre los otros GSE que en el sector popular, mostrando incluso convergencia entre este y el $\mathrm{ABC} 1$. Pero a partir de entonces, esa preocupación ha crecido más entre los grupos acomodados que en el sector popular. De hecho, como en este el aumento en tal preocupación ha sido menos abrupto, hay mayor divergencia entre dicho grupo y los otros GSE, lo que cuestiona nuestra segunda hipótesis.

Gráfica 6. Cree que la delincuencia debiese ser una de las 3 prioridades del gobierno, por GSE, 1990-2012

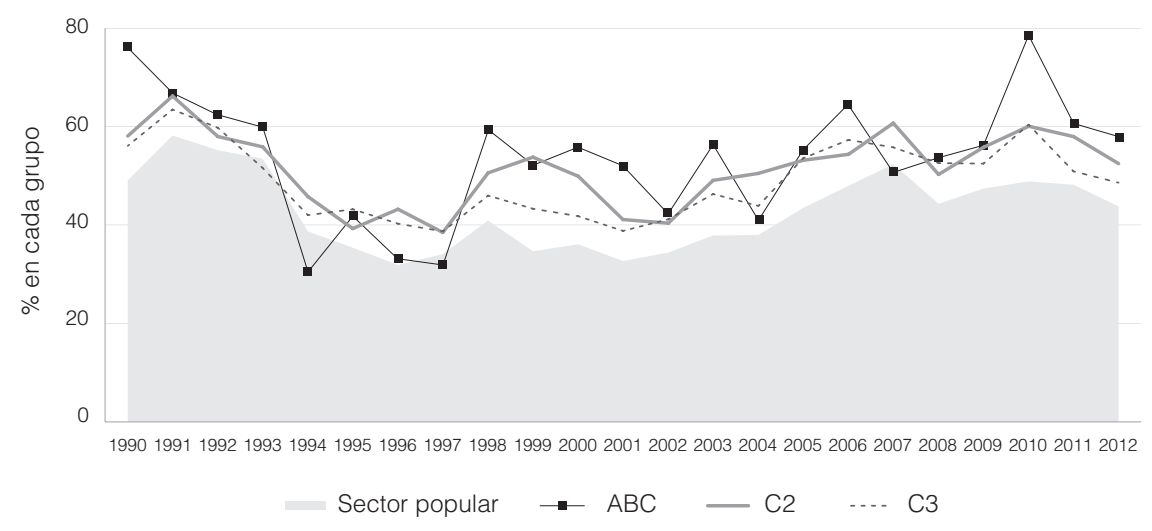

Fuente: Elaboración propia con datos de las encuestas CEP, 1990-2012, disponible en <www.cepchile.cl>.

La evolución en la preocupación por la educación presenta diferencias entre los grupos. $\mathrm{El} \mathrm{ABC1} \mathrm{y} \mathrm{C2} \mathrm{siempre} \mathrm{muestran} \mathrm{un} \mathrm{mayor} \mathrm{interés} \mathrm{en} \mathrm{la} \mathrm{educa-}$ 
ción que el sector popular. Aunque este ha mostrado una creciente preocupación por la educación, como lo sintetiza la gráfica 7, en momentos de crisis económica — como en 1998-1999— la preocupación por la educación ha caído fuertemente. Ahora bien, en la crisis de 2009, el sector popular no mostró una caída significativa en su preocupación por la educación. Entonces, hay algo de evidencia para sostener que la preocupación por la educación ha mostrado una tendencia al alza en el sector popular. Rechazamos así la primera hipótesis.

La evolución en preocupación por la educación en el sector popular y en los otros grupos se ha movido en la misma dirección, pero sin que se produzca convergencia. Aunque ha aumentado la preocupación por la educación en el sector popular, en los otros GSE también ha aumentado e incluso ha crecido con más fuerza. En años recientes, el crecimiento en la preocupación por la educación en el C3 - el grupo inmediatamente por sobre el sector popular- ha crecido más, mostrando una cierta convergencia con los GSE más altos. Pero, si bien ha crecido también el interés por la educación en el sector popular, no ha habido convergencia. Esto muestra evidencia a favor de nuestra segunda hipótesis, se mantienen las diferencias entre el sector popular y los otros grupos.

Gráfica 7. Cree que la educación debiese ser una de las 3 prioridades del gobierno, por GSE, 1990-2012

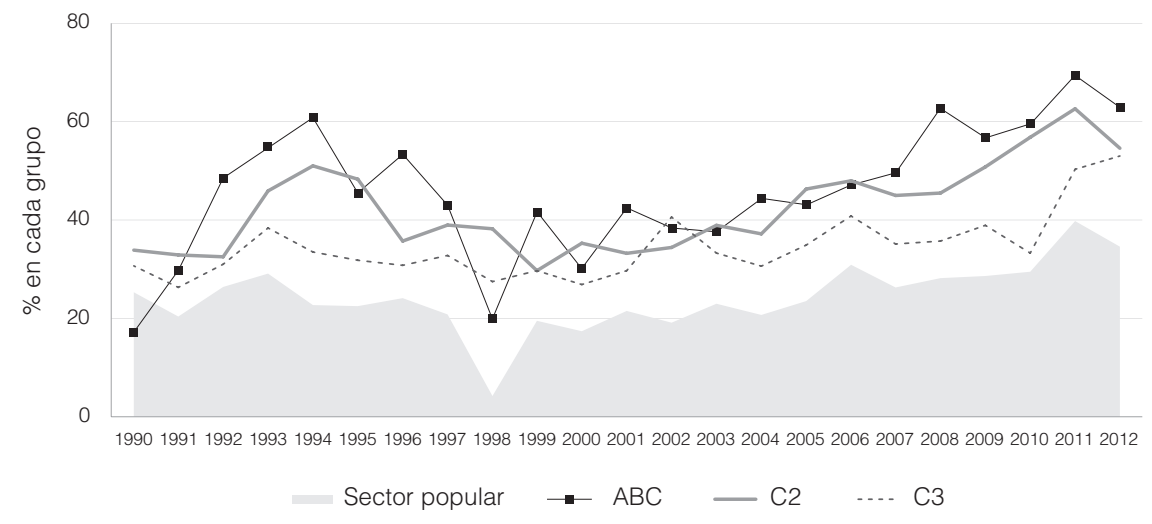

Fuente: Elaboración propia con datos de las encuestas CEP, 1990-2012, disponible en <www.cepchile.cl>.

Al compararlas con otras demandas, la preocupación por la salud muestra una sorprendente estabilidad en el tiempo. Tampoco hay grandes diferencias por GSE. La gráfica 8 muestra un fuerte aumento en la preocupación por la salud a mediados de los años noventa, pero después se estabiliza en torno al $40 \%$ en todos los grupos. No hay diferencias claras entre el sector popular y los otros 
GSE en la importancia que dan a la salud como una prioridad para el gobierno. Aunque a comienzos del periodo los otros GSE mostraban más preocupación por la salud que el sector popular, en años recientes este la presenta un poco más que los grupos $\mathrm{ABC} 1$ y $\mathrm{C} 3$. Por eso, aunque hay evidencia de estabilidad en el sector popular - y también en los otros GSE- en sus preocupaciones por la salud (hipótesis 1), también la hay de que la leve caída de la salud como tema prioritario ha sido mayor en otros GSE (hipótesis 2). Por consiguiente, se acoge la primera hipótesis pues la preocupación del sector popular por políticas públicas de salud ha sido estable en gran parte del periodo, y se rechaza la hipótesis 2, porque las diferencias de preocupación por la salud entre el sector popular y los demás GSE disminuyeron.

\section{Gráfica 8. Cree que la salud debiese ser una de las 3 prioridades del gobierno,} por GSE, 1990-2012

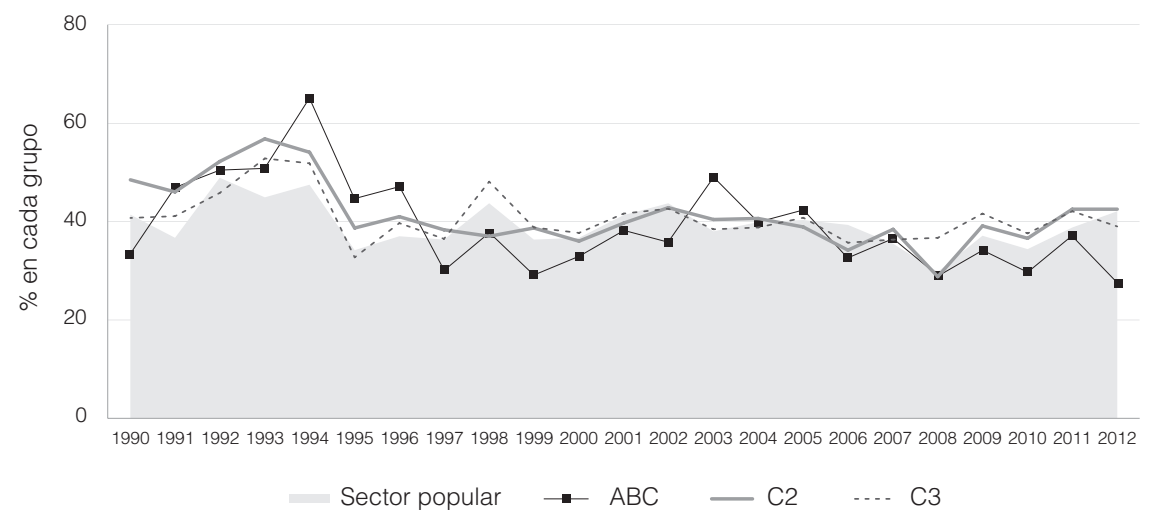

Fuente: Elaboración propia con datos de las encuestas del CEP, 1990-2012, disponible en <www.cepchile.cl>.

La preocupación por el empleo en el sector popular ha fluctuado notoriamente, aunque eso mismo ha pasado en los otros GSE. La gráfica 9 muestra una caída en la preocupación por el empleo en el sector popular a comienzos de los noventa. Pero tal preocupación cayó mucho más rápido en los otros GSE. A fines de esa década, con la crisis, la preocupación por el empleo aumentó en todos los GSE, convergiendo todos en valores altos. Pero cuando se comenzó a recuperar la economía, ese aspecto disminuyó más rápido en los GSE distintos al sector popular. Si bien es un dato que varió en el tiempo en la misma dirección en todos los GSE, las caídas en el sector popular siempre fueron menos pronunciadas. Esto posiblemente refleja que incluso en periodos de bonanza económica, el empleo se mantiene como una preocupación prioritaria en el sector popular. 
Entonces no hay evidencia para sustentar nuestra primera hipótesis. La preocupación por el empleo en el sector popular fluctuó sustancialmente. En cambio, hay evidencia mixta que soporta la segunda hipótesis. Si bien la preocupación por el empleo en el sector popular se comporta de forma similar entre los otros GSE, cae con menos fuerza en tiempos de bonanza.

Gráfica 9. Cree usted que el empleo debiese ser una de las 3 prioridades del gobierno, por GSE, 1990-2012

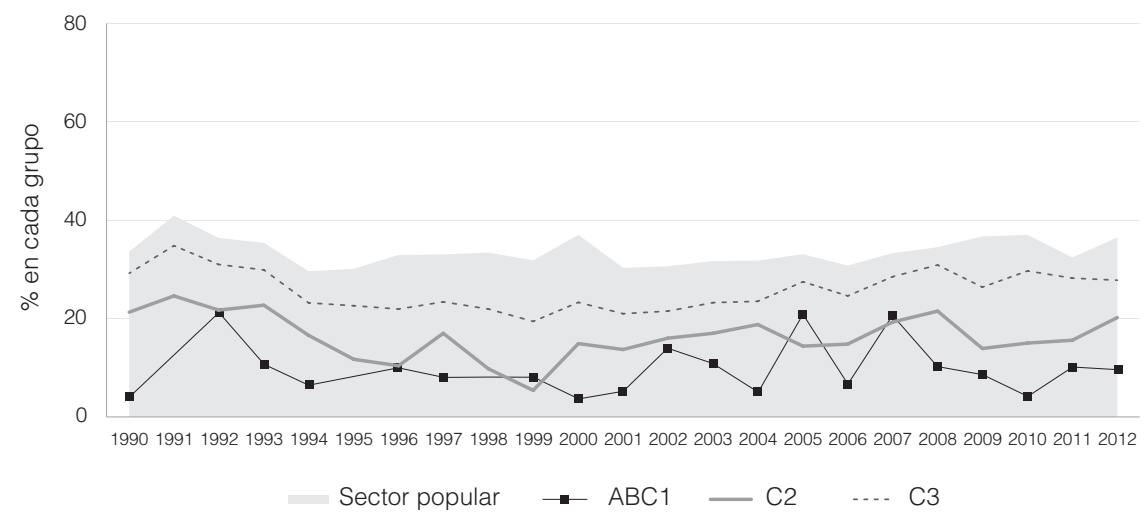

Gráfica 10. Cree usted que los sueldos debiesen ser una de las 3 prioridades del gobierno, por GSE, 1990-2012

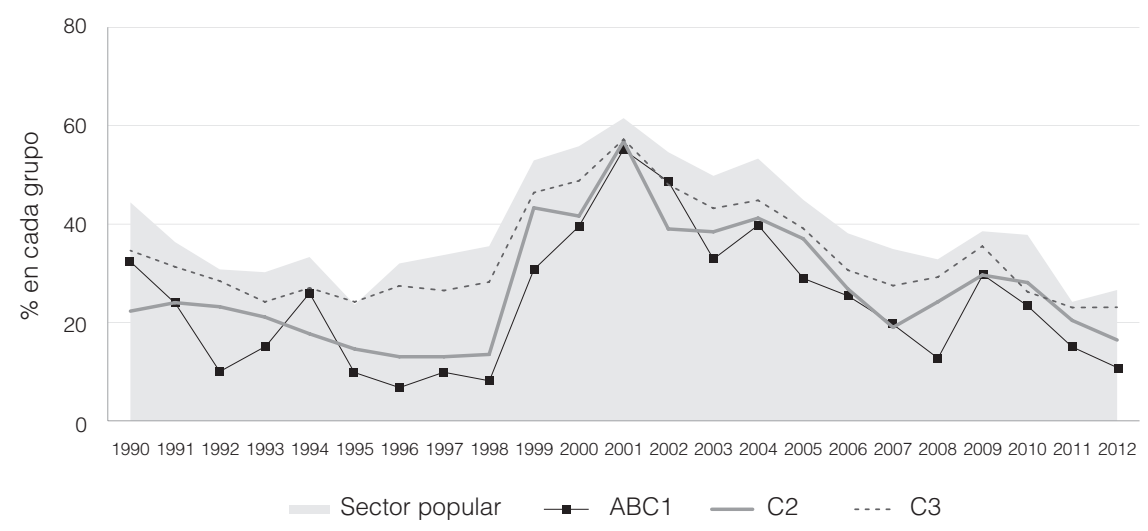

Fuente: Elaboración propia con datos de las encuestas CEP, 1990-2012, disponible en <www.cepchile.cl>.

La gráfica 10 revela que la preocupación por los sueldos siempre ha sido mayor en el sector popular que en los otros grupos. De hecho, aunque hay va- 
riación en la intensidad de preocupación por los sueldos en los otros GSE, es altamente estable en aquel sector, y siempre mayor que en los otros GSE. Aun en periodos de bonanza económica, como a mediados de los noventa o durante el gobierno de Sebastián Piñera, sigue mostrando niveles altos de preocupación por los sueldos. Así, hay evidencia para afirmar que, al menos respecto a sueldos, las preferencias del sector popular se han mantenido estables en el tiempo. Pero no es posible aseverar que las diferencias entre el sector popular y los otros grupos socioeconómicos hayan disminuido con el paso de los años. Por tanto aceptamos las hipótesis 1 y 2.

\section{Desempleo versus delincuencia}

El que la encuesta del CEP consulte sobre tres prioridades de gobierno inevitablemente introduce un problema de endogeneidad. Como las personas deben mencionar tres problemas, es probable que la aparición de uno atente contra la importancia que pudiera tener otra prioridad de política pública. La relación más evidente se da entre empleo y delincuencia. Como lo señala la gráfica 11, la evolución de ambas prioridades es inversa. Cuando sube la preocupación por el empleo, baja la preocupación por la delincuencia. Esto en parte se relaciona con que mucha gente da mayor prioridad al empleo que al combate a la delincuencia. De ahí que, cuando hay problemas económicos y aumenta el desempleo, disminuya la importancia de la delincuencia en la lista de prioridades.

Gráfica 11. Preocupación por el empleo y la delincuencia, total nacional, 1990-2012

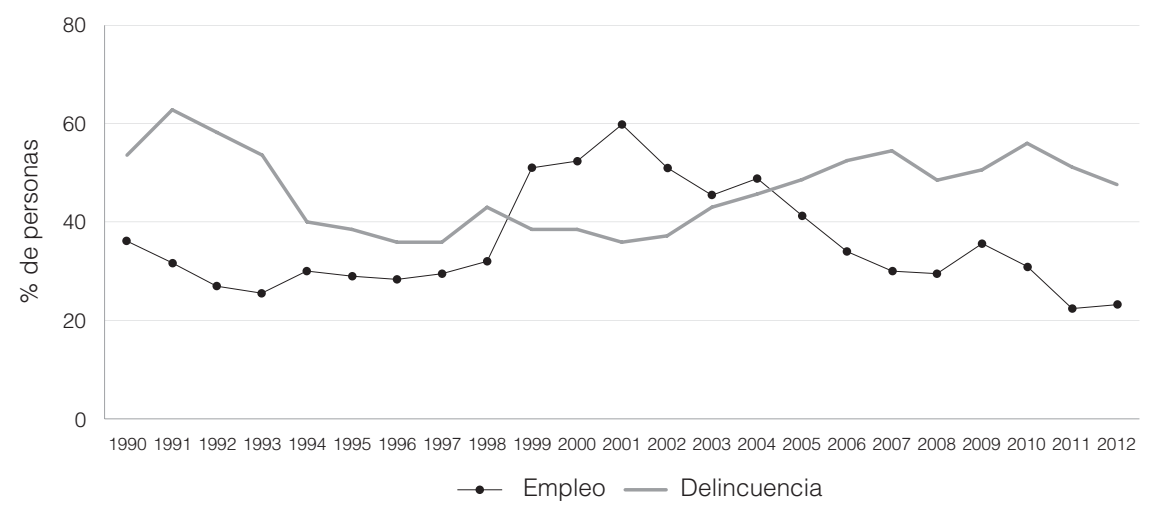

Fuente: Elaboración propia con datos de las encuestas del CEP, 1990-2012, disponible en <www.cepchile.cl>. 


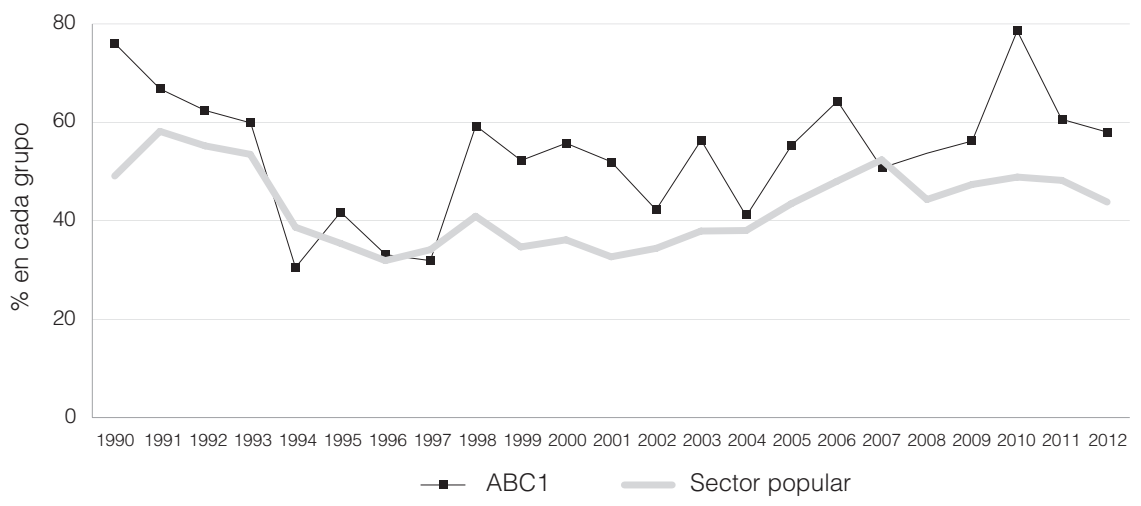

Gráfica 13. Preocupación por el empleo entre ABC1 y el sector popular, 1990-2012

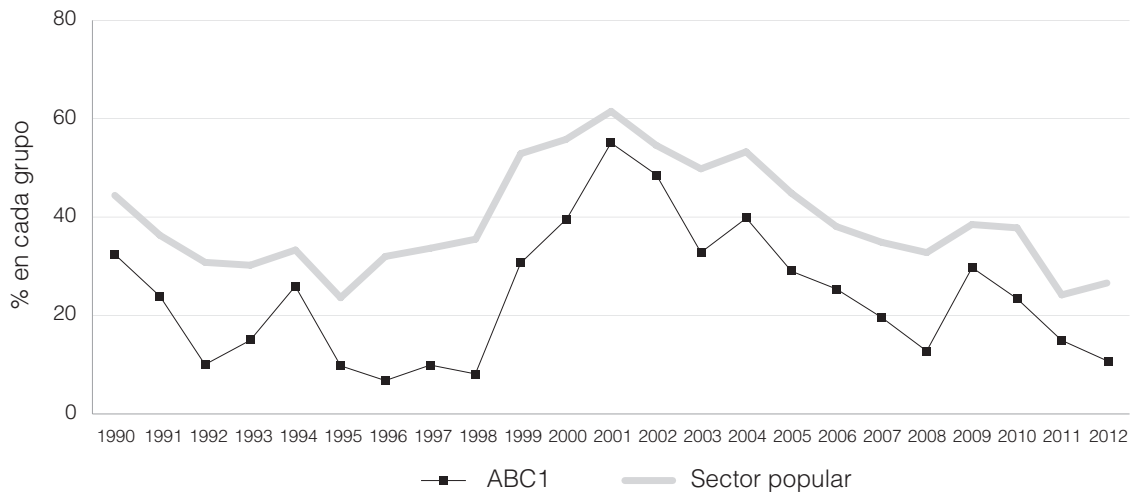

Fuente: Elaboración propia con datos de las encuestas CEP, 1990-2012, disponible en <www.cepchile.cl >.

Las gráficas 12 y 13 permiten aclarar el problema y ver cómo se diferencia la evolución de estas dos prioridades entre el sector popular y el ABC1. Para este último, la delincuencia es sistemáticamente más importante que el empleo. A la inversa, el empleo es siempre más importante para el sector popular. Aunque tanto el empleo como la delincuencia se muevan en la misma dirección para los dos grupos, la diferencia se mantiene. Es distinta la importancia relativa que cada grupo atribuye al empleo y a la delincuencia. El sector popular siempre está más preocupado por el empleo, mientras que el $\mathrm{ABC} 1$ generalmente está más preocupado por la delincuencia. Luego, no hay evidencia para confirmar nuestra primera hipótesis. La preocupación por la delincuencia y el empleo 
varían en el sector popular. Pero sí confirmamos la segunda hipótesis, las diferencias iniciales entre el sector popular y otros grupos se mantienen.

\section{Perspectivas económicas}

Las encuestas del CEP también recaban información sobre las perspectivas económicas. Una pregunta recoge la opinión sobre la economía en un año más. Las respuestas son que la economía mejorará, no cambiará o empeorará. La gráfica 14 muestra la percepción de empeoramiento. La perspectiva futura del sector popular ha variado en el periodo. Pero sistemáticamente este grupo es más pesimista que los otros. De hecho, a mediados de los noventa, cuando los otros GSE mostraban una tendencia clara a la baja en el pesimismo, el sector popular mostraba niveles más altos para el mismo aspecto. Después del cambio de siglo, el pesimismo en el sector popular convergió con el de los otros GSE. A diferencia de la crisis de fines de los noventa, cuando aquel fue más pesimista que los segundos, en la crisis de 2008, el aumento en el pesimismo hizo que todos los grupos convergieran. En años recientes, cuando este ha caído, lo ha hecho menos en el sector popular. Entonces, así como no tenemos evidencia para confirmar nuestra primera hipótesis — no hay estabilidad en el pesimismo del sector popular - tampoco podemos confirmar que las diferencias iniciales en el pesimismo del sector popular y los otros GSE se hayan mantenido.

Gráfica 14. Cree que la economía empeorará en un año más, por GSE, 1990-2012

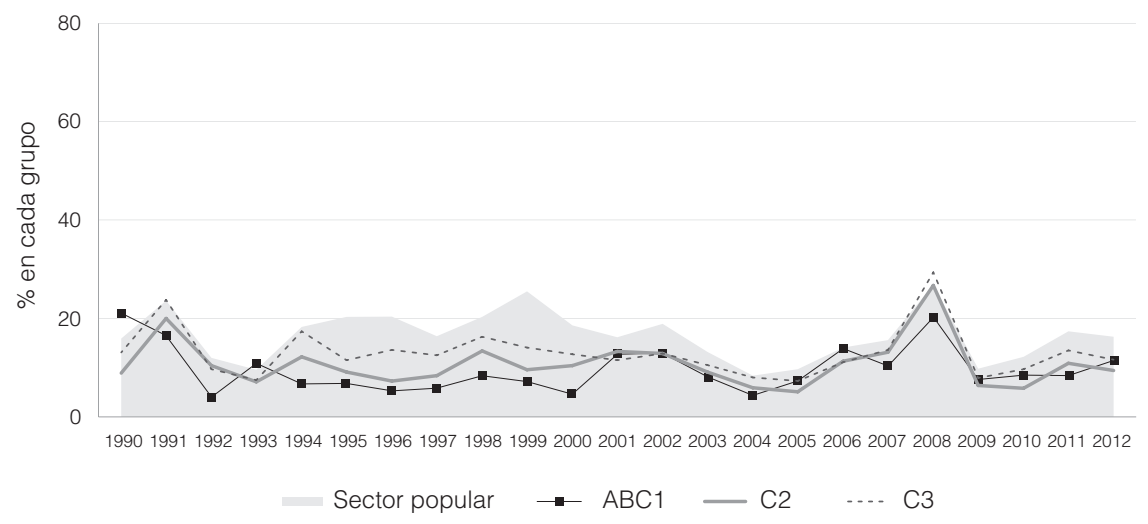

Fuente: Elaboración propia con datos de las encuestas CEP, 1990-2012, disponible en <www.cepchile.cl>. 


\section{Conclusiones}

En Chile, durante los últimos 25 años, el sector popular ha cambiado. Aunque en algunos ámbitos ha evolucionado a la par que el resto de la sociedad, en la mayoría de los indicadores y dimensiones se evidencia que mantiene diferencias importantes respecto de los otros grupos socioeconómicos. Si bien la identificación del sector popular con la Concertación disminuye, al igual que en otros grupos, y en las preocupaciones por políticas públicas de salud no existen grandes diferencias, los demás indicadores confirman que este sector sí tiene diferencia con los demás grupos.

El sector popular sigue siendo más reacio a apoyar candidatos presidenciales de la Alianza y más proclive a apoyar a los de la Concertación. También tiende a apoyar con menos fuerza que otros grupos a los presidentes, salvo en el caso de Bachelet. Muestra un mayor interés en temas relacionados con el empleo y los sueldos. A su vez, le importan menos que al ABC1 los asuntos relacionados con la delincuencia. De ahí que sea razonable estudiarlo como un grupo social distinguible a partir de sus preocupaciones y prioridades. Aunque Chile haya avanzado en desarrollo económico y reducción de pobreza, hay suficiente evidencia para aseverar que el sector popular sigue presentando características y preferencias diferentes a los otros grupos de la sociedad.

\section{Referencias}

Adimark, s.f., Mapa socio-economico de Chile. Nivel socioeconómico de los hogares del país basado en datos del Censo, Santiago, Adimark.

Arriagada, Genaro, 1974, De la vía chilena a la vía insurreccional, Santiago, Editorial del Pacífico.

Atkinson, W., 2010, "Class, Individualisation and Perceived (Dis)advantages, Not Either/Or but Both/And?", Sociological Research Online, vol. 15, núm. 4.

Bauman, Z., 2001, The individualized society, Polity Press.

Bourdieu, Pierre, 2000, Poder, derecho y clases sociales, Santiago, Desclée de Brouwer.

Bourdieu, P., 1987, "What Makes a Social Class? On the Theoretical and Practical Existence of Groups”, Berkeley Journal of Sociology, vol. 32, núm. 1, pp. 1-17.

Campbell, Angus, Pihilip E. Converse, Warren E. Miller, y Donald E. Stokes, 1960, The American Voter, Nueva York, Wiley. 
Cañas Kirby, Enrique, 1997, Proceso político en Chile. 1973-1990, Santiago, Andrés Bello.

Castañeda, Tarsicio, 1992, Combating Poverty. Innovative Social Reforms in Chile During the 1980s, San Francisco, International Center for Economic Growth.

Contreras, Dante, 2003, "Poverty and Inequality in a Rapid Growth Economy: Chile 1990-96", The Journal of Development Studies, vol. 39, núm. 3, pp. 181-200.

Crompton, R., 2010, “Class and Employment”, Work, Employment \& Society, vol. 24, núm. 1.

Dalton, Russel J., y Hans-Dieter Klingemann, 2007, "Citizens and Political Behavior”, en Russel J. Dalton y Hans-Dieter Klingemann (eds.), The Oxford Handbook of Political Behavior, Nueva York, Oxford University Press.

De Vylder, Stefan, 1976, Allende's Chile. The Political Economy of the Rise and Fall of the Unidad Popular, Cambridge, Cambridge University Press.

Debray, Régis, 1971, Conversación con Allende. ¿Logrará Chile implantar el socialismo?, México, Siglo XXI.

Garcés, Joan E., 1976, Allende y la experiencia chilena, Barcelona, Ariel.

Godoy Arcaya, Oscar, 1999, “La transición a la democracia: Pactada”, Estudios Públicos, núm. 74, pp. 79-106.

Hojman, David E., 1996, "Poverty and Inequality in Chile: Are Democratic Politics and Neoliberal Economics Good for You?", Journal of Interamerican Studies and World Affair, vol. 38, núms. 2/3, pp. 73-96.

Howarth, D., 2006, Discourse, Buckingham, Open University Press.

Jennings, M. Kent, 2007, "Political Socialization”, en Russel J. Dalton y Hans-Dieter Klingemann (eds.), The Oxford Handbook of Political Behavior, Nueva York, Oxford University Press.

Kaufman, Robert R., 1972, The Politics of Land Reform in Chile. 1950-1970. Public Policy Institutions and Social Change, Cambridge, Harvard University Press.

Kymlicka, Will, y Wayne Norman, 1997, "El retorno del Ciudadano. Una revisión de la producción reciente en teoría de la ciudadanía”, Ágora, núm. 7, pp. 5-42.

Larraín, Jorge, 2001, “El concepto de identidad”, en Jorge Larraín (ed.), Identidad chilena, Santiago, LOM, pp. 7-48. 
Lau, Richard R., y David P. Redlawsk, 2006, How Voters Decide. Information Processing During Elections Campaigns, Nueva York, Cambridge University Press.

Leiva, Fernando Ignacio, y James Petras, 1986, "Chile's Poor in the Struggle for Democracy", Latin American Perspectives, 51, vol. 13, núm. 4, pp. 5-25.

Lewis-Beck, Michael S., y Mary Stegmaier, 2007, “Economic Models of Voting”, en Russel J. Dalton y Hans-Dieter Klingemann (eds.), The Oxford Handbook of Political Behavior, Nueva York, Oxford University Press, pp. 518-537.

López, Miguel Ángel, 2004, "Conducta electoral y estratos económicos: el voto de los sectores populares en Chile”, Política, núm. 43 (primavera), pp. 285-298.

Loveman, Brian, 1974, "Unidad Popular in the Countryside: Ni Razón, Ni Fuerza”, Latin American Perspectives, vol. 1, núm. 2, pp. 147-155.

Marx, Karl, 1997, El capital, Bogotá, Panamericana.

Mata, María Cristina, 1991, "Memorias de la recepción. Aproximaciones a la identidad de los sectores populares”, Diálogos de la Comunicación, núm. 30 (junio).

Matterlat, Armand, Carmen Castillo y Leonardo Castillo, 1970, La ideología de la dominación en una sociedad dependiente, Santiago, Ediciones Signos.

Millán, Henio, 2001, "Crisis y pobreza extrema en México. ¿Provoca pobreza el modelo de desarrollo?", Perfiles Latinoamericanos, núm. 19, pp. 181-203.

Morales, Mauricio, 2012, “The Concertación's Defeat in Chile’s 2009-2010 Presidential Elections”, Latin American Politics and Society, vol. 54, núm. 2, pp. 79-107.

Morales, Mauricio, 2008, "La primera mujer presidenta de Chile. ¿Qué explicó el triunfo de Michelle Bachelet en las elecciones de 2005-2006?", Latin American Research Review, vol. 43, núm. 1.

Morales, Mauricio, y Jorge Saldaña, 2009, "Aprobación presidencial en Chile. Los ricos por Lagos, los pobres por Bachelet", en ICsO-Udp, Chile 2008. Percepciones y actitudes Sociales, Santiago, Universidad Diego Portales.

Moulián, Tomás, 1997, El Chile Actual. Anatomía de un mito, Santiago, LOM/Arcis.

Navia, Patricio, 2010, "Chile: Democracy to the Extent Possible", Latin American Research Review, núm. 45 (número especial), pp. 298-328. 
Oxhorn, Philip D., 1995, Organizing Civil Society. The Popular Sector and the Struggle for Democracy in Chile, University Park, Pennsylvania State University Press.

Oxhorn, Philip D., 1991, “The Popular Sector. Response to an Authoritarian Regime. Shantytown Organizations since the Military Coup”, Latin American Perspectives, 67, vol. 18, núm. 1, pp. 66-91.

Petras, James, y Morris Morley, 1975, The United States and Chile. Imperialism and the Overthrow of the Allende Government, Nueva York, Monthly Review Press.

Petras, James, y Hugo Zemelman Merino, 1972, Peasants in Revolt. A Chilean Case Study, 19651971, Austin, Institute of Latin American Studies/University of Texas Press.

Petras, James, y Maurice Zeitlin, 1967, "Miners and Agrarian Radicalism”, American Sociological Review, vol. 32, núm. 4, pp. 578-586.

PNud, 2002, Desarrollo Humano en Chile. Nosotros los chilenos, un desafio cultural, Santiago, Programa de las Naciones Unidas para el Desarrollo.

PNUD, 1998, Informe de Desarrollo Humano en Chile. Las paradojas de la modernización, Santiago, PNUD.

Portales, Felipe, 2000, Chile. Una democracia tutelada, Santiago, Sudamericana.

Posner, Paul W., 2008, State, Market and Democracy in Chile, Nueva York, Palgrave McMillan.

Posner, Paul W., 2003, "Local Democracy and Popular Participation: Chile and Brazil in Comparative Perspective", Democratization, vol. 10, núm. 3, pp. 39-67.

Rojas, M., 2010, "Mejorando los programas de combate a la pobreza en México: del ingreso al bienestar", Perfiles Latinoamericanos, núm. 35 (enero/junio).

Rojas Sandford, Robinson, 1975, The Murder of Allende and the End of the Chilean Way to Socialism, Nueva York, Harper and Row, Publishers.

Salazar, Gabriel, 2011, En el nombre del poder popular constituyente, Santiago, LOM.

Segovia, C., A. Haye, R. González, J. Manzi y H. Carvacho, 2008, “Confianza en instituciones políticas en Chile: un modelo de los componentes centrales de juicios de confianza”, Revista de Ciencia Política (Santiago), vol. 28, núm. 2, pp. 39-60.

Skeggs, Beberley, 2004, Class, Self, Culture, Psychology Press. 
Sunkel, Guillermo, 1987, "La representación del pueblo en los diarios de masas", Diálogos de la Comunicación, núm. 17 (junio).

Taylor, Charles, 1993, El multiculturalismo y la politica del reconocimiento, México, Fondo de Cultura Económica.

Torres Dujisin, Isabel, 2010, El imaginario de las elites y los sectores populares. 1919-1922, Santiago, Editorial Universitaria.

Tugendhat, E., 1996, "Identidad: personal, nacional y universal”, Personas y Sociedad, vol. 10, núm. 1, pp. 29-40.

Valdés, Teresa, 1988, Venid, benditas de mi Padre. Las pobladoras, sus rutinas, sus sueños, Santiago, Flacso Chile.

Vázquez, José Juan, y Sonia Panadero, 2009, “Atribuciones causales de la pobreza en los países menos desarrollados", Perfiles Latinoamericanos, núm. 34, pp. 125-140.

Weber, Max, 1922, Economía y sociedad, México, Fondo de Cultura Económica.

Zeitlin, Maurice, y James Petras, 1970, “The Working-Class Vote in Chile: Christian Democracy versus Marxism”, British Journal of Sociology, vol. 21, núm. 1, pp. 16-29.

Recibido el 20 de julio de 2011. Aceptado el 24 de octubre de 2014. 